\title{
Influence of Allergic Disorders on Physical Development
}

\author{
R. Pawlinska-Chmara ${ }^{1}$, I. Wronka² \\ ${ }^{1}$ Department of Biotechnology and Molecular Biology, Opole University, Opole, Poland; ${ }^{2}$ Department of Anthropology, \\ Jagiellonian University, Krakow, Poland
}

\begin{abstract}
The aim of the paper was to asses the relationship between socioeconomic status, the prevalence of allergy and physical development. The data were obtained from 478 female students and 195 male students aged 19-24. The prevalence of allergy in the group surveyed was $14.6 \%$ (14.6\% in women and $14.4 \%$ in men). Allergic diseases were more frequent in students of high socioeconomic status. The results of the analysis of variance did not show any significant differences in anthropometric characteristics between students with and without allergies. However, women and men with allergies diagnosed are on average shorter than people without allergies. The dependency is also visible after adjusting for socioeconomic status. As for the equal status groups, the people with allergies are always shorter than those without allergies. Summarizing, the results of the tests presented indicate that allergic diseases may affect the growing process. However, upon providing appropriate conditions, the growth of children with allergy is not different from the control population.
\end{abstract}

Key words: allergy, socioeconomic status, body height, BMI

\section{INTRODUCTION}

Studies on the causes and effects of allergic diseases have become the topic of several papers recently. Genetic predispositions are listed among the factors having significant effects on allergy appearance $[1,2]$. Allergy is a polygenic disease and its occurrence is affected by environmental factors, most of all those related to civilization progress: air and water pollution, adding preservatives, artificial colorants and other additives to food, exposure to tobacco smoke, mass application of antibiotics. A significant role is also attributed to factors related to life style, such as low physical activity, frequent staying indoors with closed windows or airconditioning, and diet based on highly processed food. Allergy undoubtedly is a civilization disease and the growth of its frequency is mostly observed in countries of high life standard $[3,4,5,6]$.

Allergy, like any other disease may affect the biological development. It is difficult, however, to assess the correlation between allergic diseases and physical growth, when we are not in possession of complete data until the end of growth process. Acceleration or retardation of the development observed during child- hood not necessarily will continue throughout the whole childhood and adolescence. Persons who grow fast in their childhood often mature earlier and earlier finish the growth process, in consequence remaining short as adults. The catch-up phenomenon is also observed, thanks to which the child makes up for developmental delays caused by bad living conditions or diseases [7]. In the present study, therefore, correlation between the occurrence of allergy and adult body size has been analyzed. Two questions were considered. Firstly, it was checked whether the prevalence of allergy is higher in persons from families with high socialeconomic status. Secondly, it was estimated whether the occurrence of allergy affects the biological growth.

\section{MATERIAL AND METHODS}

The study was approved by an institutional Ethics Committee and was performed in accordance with guidelines of the Declaration of Helsinki of 1975 for Human Research. The data to be analyzed were obtained from students of the Jagiellonian University in Krakow and the Opole University in Opole, Poland. A total of 478 women and 195 men aged 19-24 were examined. Height and body mass were measured in each person and BMI calculated. Information on the socioeconomic status (SES) and allergy occurrence was collected by means of a questionnaire. The socioeconomic status was determined by variables commonly used in Poland: place of residence in childhood and parents' education. In addition, the respondents were asked for self-assessment of the financial standing of their families. To determine the allergy occurrence, the following question was asked: were you diagnosed with allergy during medical examination and what factors are you allergic to? Particular attention was paid to the fact that the responses should concern the cases of allergy found by physicians only.

To determine the significance of differences in the prevalence of allergy, depending on the social variables, the Chi2 test was applied. The differences in anthropometric parameters, depending on allergy occurrence were assessed by means of a multi-factor analysis of variance.

\section{RESULTS}

The prevalence of allergy in the study group was $14.6 \%$, (14.6\% in women and $14.4 \%$ in men). Due to 
the lack of significant differences, the analysis was continued disregarding the division into gender in the further part of the paper (Table 1).

Allergic rhinitis was found in most of the persons surveyed (47), food allergy in 5 students, both types of allergy occurred in 6. Atopic dermatitis occurred in 9 persons. The most frequent allergens were house dust mites, pollens of trees, shrubs and grass, dog and/or cat fur and molds. Foods included strawberries, cocoa and chocolate and preservatives contained in foods. Additionally, 3 people, 2 of whom with allergic rhinitis declared allergies to drugs (penicillin, sulphamidin), 2 people were allergic to apitoxin.

The prevalence of allergy in the students who lived in the city in their childhood was much higher in comparison with the students who lived in the country (Table 1). A significantly larger number of cases of allergies were recorded in students from high SES families than in those from low SES families (Table 1). The prevalence of allergy in the person surveyed was varied, depending on the complex assessment of the socioeconomic status, but not on the detailed elements contained in this indicator, such as parents' education.
Body height and relative body mass (determined in relation to height) are strongly ecosensitive charactericts. Their values are largely affected by the nutrition method, both quantitatively and qualitatively; physical activity and incidence of diseases in childhood. The above mentioned factors are, in turn, dependent on the socioeconomic status. This is the reason for considering another factor - the complex social-economic status assessment index - while determining the influence of allergy occurrence on the adult height and BMI.

The results of the two-factor analysis of variance did not show any significant differences in anthropometric parameters between people with and without allergies (Table 2). However, women and men diagnosed with allergies were, on average, shorter than people without allergies (Table 2). The dependency was also visible upon adjusting for the socioeconomic status. As for the equal status groups, the people with allergies were always shorter than those without allergies. In case of the BMI, among students with allergy BMI values were, on average, slightly lower than among students without allergy (Table 2).

Table 1. The prevalence of allergy among children in relation to SES and lifestyle.

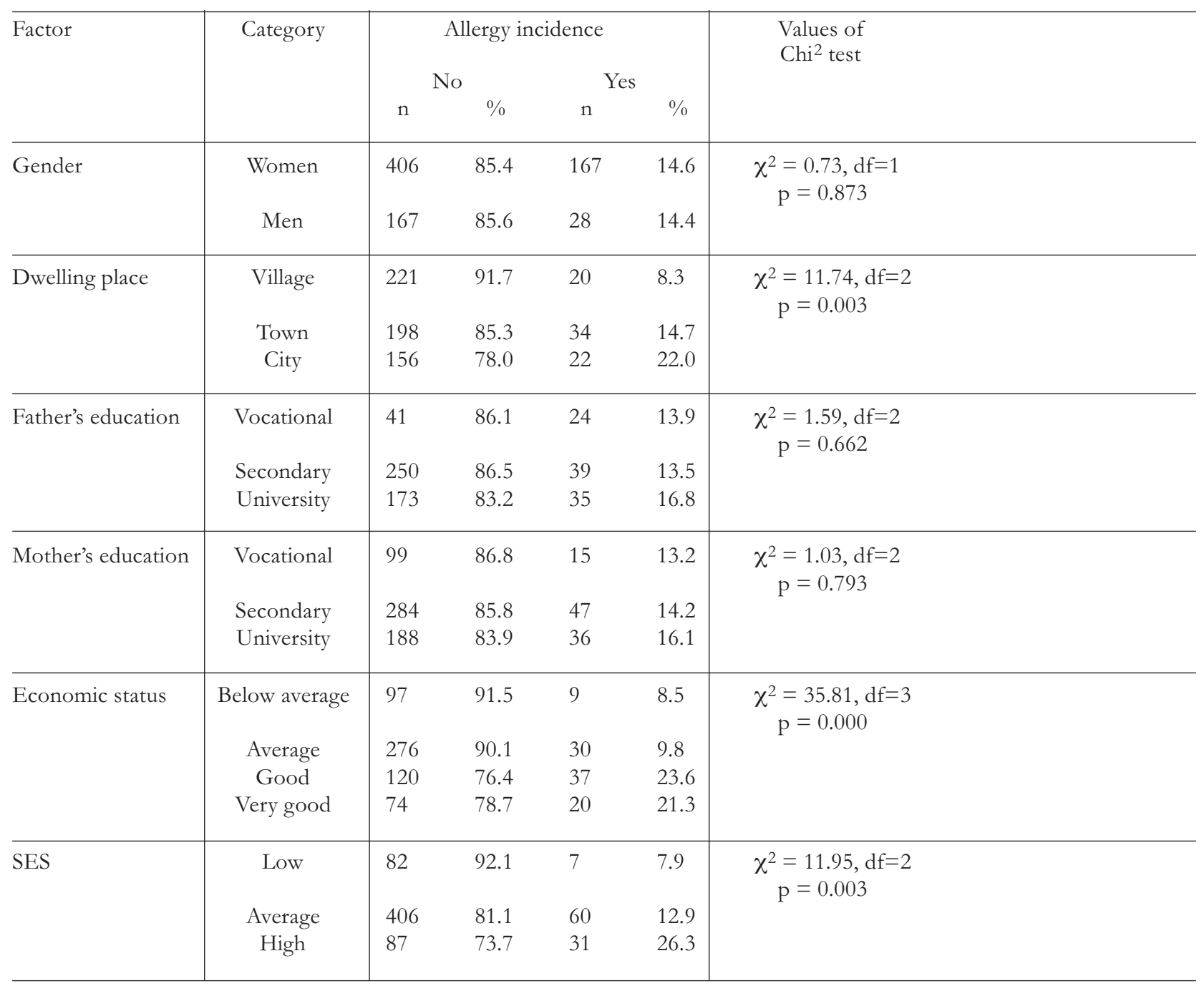


Table 2. Variation in mean height and BMI in relation to social background and the occurrence of allergic diseases.

\begin{tabular}{|c|c|c|c|c|c|c|c|}
\hline \multirow[b]{2}{*}{ Factor } & \multirow[b]{2}{*}{ Category } & \multicolumn{3}{|c|}{ Women } & \multicolumn{3}{|c|}{ Men } \\
\hline & & $\mathrm{n}$ & Mean & SD & $\mathrm{n}$ & Mean & SD \\
\hline
\end{tabular}

BODY HEIGHT

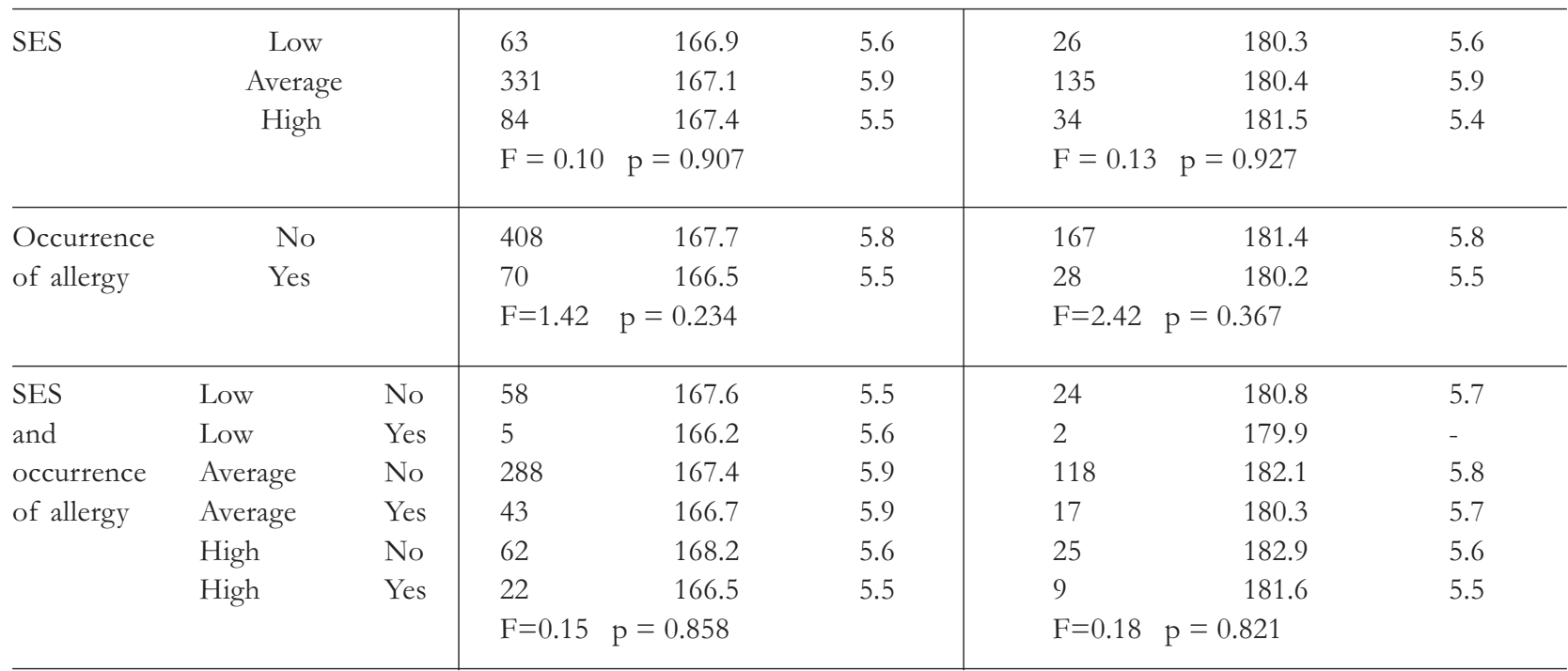

BODY MASS INDEX

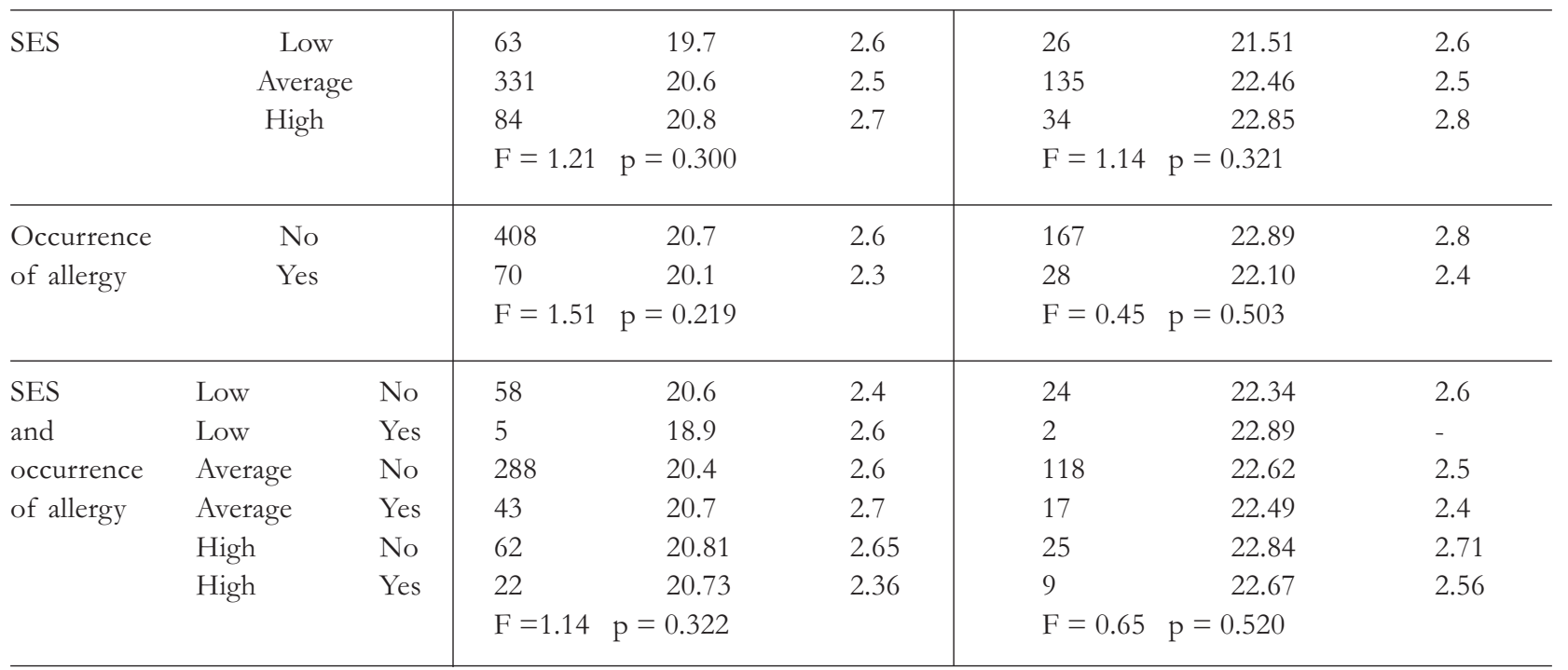

\section{DisCUSSION}

Allergy disorders have a multiorgan character, characterized by various symptoms occurring with different intensity. Allergy disorders may manifest at various stages of personal development. According to Debor's theory, the 'allergy march' can be observed. At infant age and in early childhood, the symptoms of food allergy are most often observed, due to immature alimentary system and introducing particular foods for the first time. These are the periods when skin symptoms also appear. At later age, dermal allergy, allergic conjunctivitis, rhinitis, and asthma predominate [8]. Allergic rhinitis dominates in students, while the cases of food allergy are rare. However, the fact that many of the surveyed suffered from food allergies in their childhood, cannot be excluded.

Allergic diseases were more frequent in students of high social-economic status. These findings accord with the results of other studies and cannot be explained just by a higher ability to detect the disease in persons of high socioeconomic status [9, 10, 11]. A higher socioeconomic status is correlated with a lifestyle not necessarily beneficial for an allergic person. The allergic disease incidence is enhanced by some elements related to the conditions and lifestyle characteristic for this group, such as air conditioning, closed rooms, or little time spent outdoors. People of high status more often use finished foods, most of them highly processed. 
It has been proven that the socioeconomic status not only bears on the diagnosis of allergic diseases, but also on history of allergy [12, 13]. Although allergies are detected in people of high socioeconomic position, the disease usually has a milder history. That concerns the number of attacks in a month or the intensity of them. People of a good financial standing can afford more expensive medicines, holiday travels to regions of low air pollution, the use of vitamins and minerals or special food products. The last two factors are significant in case of food allergies, where the application of the elimination diet is necessary. In case of the elimination of numerous foods, this may cause deficiency of some vitamins and minerals, necessary for the normal development. Also, the medicines applied to cure the allergy may affect the biological development of allergic children $[13,14]$.

Most of the studies do not indicate the statistical occurrence of significant differences in the level of development between children with or without allergies $[16,17]$. A slightly higher body mass, however, was observed in the former, which probably is a consequence of taking medicaments [18]. The results are contradictory in case of body height. Slightly higher values of height were found in allergic children from the city Poznan in Poland [19]. This may be, however, a consequence of rapid biological development. Most of the allergic children were from families of high socioeconomic status and this is the group in which the development acceleration is most often observed in. Some scientists posit that the allergy occurrence can be a consequence of rapid development and short period of maturing of the immunological system. The hypothesis has been confirmed by a significantly earlier age of sexual maturing noted in girls with allergies and asthma compared with healthy girls [20].

Most of the studies, however, indicate the lack of differences in the development, depending on allergic disease occurrence. It presumably is correlated with the status. Parents with high earnings and extensive knowledge on proper child care and pro-health prophylactics are able to provide the child with appropriate conditions for development that allow the child to realize its genetic potential, despite the occurrence of the disease. The tests presented herein were carried out in adults. Their growing process was finished and body height value is a result of life conditions and style throughout the entire process of childhood and youth. The results, compliant with the studies of other authors, did not present any significant differences in body height, between the allergic and non-allergic people. This tendency also is visible upon dividing the subjects into uniform groups by status. Interesting is the fact that the size of differences is much alike, regardless of whether we consider them in the group of high or low status. This suggests that allergic diseases may affect the growing process. Shorter stature in allergic people may also be a consequence of their faster maturing

In case of the BMI, no differences depending on allergy occurrence were observed. This characteristic is much more dependent on the current living condi- tions and style than on the living conditions of the preceding development periods.

The limitations of the current analysis should be mentioned. The study concerned a selected group students. In Poland, the majority of secondary school leavers continue education at universities, but not all of them. The socioeconomic characteristics of the subjects show that, although they represent groups of various positions, the people of the lowest income were not among them.

Summarizing, the results of the tests presented in this study indicate that allergic diseases may affect the growing process. However, upon providing appropriate conditions, the growth of children with allergies is not different from the control population.

Conflicts of interest: No conflicts of interest were declared in relation to this paper.

\section{REFERENCE}

[1] Steinke JW, Rich SS, Boris L. Genetics of allergic disease. J Allergy Clin Immunol 2008; 121: 384-7.

[2] Pawlinska-Chmara R, Wronka I, Muc M. Prevalence and correlates of allergic diseases among children. J Phys Pharmacol 2008; 59: 549-56.

[3] Bateman ED, Jithoo A. Astma and allergy - a global perspective. Allergy 2007; 62: 213-5.

[4] Bjorksten B. Risk factors in early childhood for the development of atopic diseases. Allergy 2004; 49: 400-7.

[5] Ernst P. Socioeconomic status and childhood atopy. Can Resp J 1996; 3 (1): 53-7.

[6] Gold DR. Allergy. The prize paid for longevity and social wealth? J Allergy Clin Immunol 2006; 117: 148-50.

[7] Bogin B. Patterns of Human Growth. Cambridge University Press 1999

[8] Bergmann KE, Bergmann RL, Wahn V. The allergy march: from food to pollen. Enviromen Toxicol Pharmacol 1997; 4: 79-83.

[9] Arshad SH, Hide DW. Effect of environmental factors on the development of allergic disorders in infancy. J Allergy Clin Immunol 1992; 90: 235-41.

[10] Cullinan P, Tavlor N. Asthma in children: Environmental factors. Br Med J 1994; 308: 1585-96.

[11] Heinrich J, Popescu MA, Wjst M, Goldstein IF, Wichmann HE. Atopy in children and parental social class. Am J Pub Health 1998; 88: 1319-24.

[12] Lewis SA, Weiss ST, Platts-Mills E, Syring M, Gold D. Association of specific allergen sensitization with socioeconomic factors and allergic disease in a population of Boston women. J Allergy Clin Immunol 2001; 107: 61523.

[13] Strachan DP. Family size, infection and atopy: the first decade of the "hygiene hypothesis". Thorax 2000; 52: 1018

[14] Agertoft L, Pedersen S. Effect of long-term treatment with inhaled budeosonide on adult height in children in asthma. N Eng J Med 2000; 343: 1054-62.

[15] Hauspie R, Susanne C, Alexander F. Maturational delay and temporal growth retardation in asthmatic boys. J Allergy Clin Immunol 1977; 59: 200-9.

[16] Borowska-Struginska B, Gwardys T. Physical development if children and adolescents with allergic disorders, result preliminary. Polish J Enviromen Stud 2008; 17: $47-$ 50.

[17] Moudiou T, Theophilatou D, Prifitis K, Papadimitriou A. Growth of asthmatic children before long-term treatment with inhaled corticosteroids. J Asthma 2003; 40: 66771. 
[18] Puch EA, Krenz-Niedbala M, Brebowicz A. Growth status of children with allergy symptoms. Polish J Enviromen Stud 2008; 17: 327-32.

[19] Von Mutius E, Schwartz J, Neas LM, Weiss ST. Relation of body mass index to asthma and atopy in children. The National Health and Nutrition Examination Study III. Thorax 2001; 56: 835-9.

[20] Drosdzol A, Skrzypulec V, Wilk K, Nowosielski K. The influence of bronchial asthma on sexual maturation of girls. J Phys Pharmacol 2007; 58: 155-63.
Address for correspondence:

R. Pawlinska-Chmara Ph.D

Department of Biotechnology and Molecular Biology

Opole University

Kominka St.

45-035 Opole

Poland

Phone: $\quad$ +48 774539110 ext. 148

Fax: $\quad+48774545467$

E-mail: Roma@uni.opole.pl 